\title{
Heavy-ion beam irradiation inhibits invasion of tongue squamous cell carcinoma Tca8113 cells
}

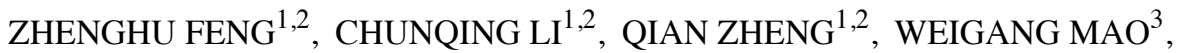 \\ TAO $\mathrm{LI}^{1,2}$, LONG XING ${ }^{1,2}$ and QIANG $\mathrm{LI}^{4}$ \\ ${ }^{1}$ Key Laboratory of Oral Diseases of Gansu Province, School of Stomatology; \\ ${ }^{2}$ Key Laboratory of Stomatology of State Ethnic Affairs Commission, Northwest Minzu University, \\ Lanzhou, Gansu 730030; ${ }^{3}$ School of Stomatology, Lanzhou University; \\ ${ }^{4}$ Institute of Modern Physics, Chinese Academy of Sciences, Lanzhou, Gansu 730000, P.R. China
}

Received March 20, 2018; Accepted July 11, 2019

DOI: 10.3892/ol.2019.10761

\begin{abstract}
Tongue squamous cell carcinoma (TSCC) is a common malignant tumor type with aggressive biological characteristics, located in the oral and maxillofacial region. Vascular endothelial growth factor (VEGF) and matrix metalloproteinases (MMPs) have been implicated in the invasion and metastasis of various malignant tumor types, such as lung cancer and gastric carcinoma. High linear energy transfer (LET) particle irradiation has several advantages over conventional X-rays in suppressing the invasion and metastasis of malignant tumors. The objective of the present study was to investigate the effects of high-LET carbon ions and low-LET X-rays on the expression of VEGF and MMPs, and to identify the associated mechanisms in the Tca8113 TSCC cell line. Tca8113 cells were irradiated with carbon ions or X-rays at doses of 1 and $4 \mathrm{~Gy}$. An immunofluorescence assay indicated that VEGF expression was notably decreased at 24 and $48 \mathrm{~h}$ after heavy ion irradiation compared with irradiation with conventional X-rays. The expression of MMP-2 and MMP-9 also decreased in a dose-dependent manner following heavy ion irradiation. These findings indicate that compared with low-LET X-ray irradiation, high-LET carbon ions possess higher biological efficacy in inhibiting the invasive ability of Tca8113 cells via reduction of VEGF, MMP-2 and MMP-9 expression.
\end{abstract}

Correspondence to: Dr Qiang Li, Institute of Modern Physics, Chinese Academy of Sciences, 509 Nanchang Road, Lanzhou, Gansu 730000, P.R. China

E-mail: liqiang@impcas.ac.cn

Abbreviations: TSCC, tongue squamous cell carcinoma; VEGF, vascular endothelial growth factor; LET, linear energy transfer; MMP, matrix metalloproteinase; ECM, extracellular matrix

Key words: carbon-ion irradiation, matrix metalloproteinase-2, matrix metalloproteinase-9, tongue squamous cellular carcinoma, vascular endothelial growth factor

\section{Introduction}

Tongue squamous cell carcinoma (TSCC) is the most common type of oral squamous cell carcinoma and exhibits aggressive biological characteristics (1-3). Despite advances in therapeutic techniques and management, TSCC has a poor prognosis due to the frequent incidence of invasion and metastasis in the early stages (4). Radiotherapy, as an important adjuvant treatment modality, reduces relapse rates and increases survival rates in patients with TSCC; however, severe complications, including mucositis, hyposalivation, taste loss, osteoradionecrosis, dysphagia and swallowing deterioration, limit the success of clinical application (5-7). Therefore, it is important to understand the mechanisms underlying the growth, invasion and metastasis of these tumors in order to develop novel therapeutic strategies against TSCC.

High linear energy transfer (LET) heavy ion irradiation, including carbon ions, has several advantages over conventional low-LET X-rays, as it delivers a high dose to the tumor, while minimizing the dose delivered to surrounding healthy tissues (8). Therefore, heavy ion radiotherapy is increasingly being regarded as an effective therapeutic strategy for suppressing the invasive and metastatic radiation-resistant malignant tumors $(9,10)$. Clinical data have demonstrated that numerous types of tumor of various pathological types, including squamous cell carcinoma, lung cancer and non-squamous cell types, such as adenocarcinoma, adenoid cystic carcinoma, bone and soft-tissue tumors, can be treated with carbon ions (10). Carbon ion radiation suppresses the angiogenesis potential of human endothelial ECV304 cells via inhibiting matrix metalloproteinase (MMP)-2 activity, and additionally suppresses the migration and invasion of human lung adenocarcinoma A549 cells by downregulating expression of the anillin gene $(11,12)$. However, heavy ion radiation has not received much attention in oral squamous cell carcinoma, which is well known for its invasive and metastatic characteristic $(3,4)$. Angiogenesis and degradation of the extracellular matrix (ECM) serve an important role in tumor growth, invasion and metastasis of TSCC (13). Vascular endothelial growth factor (VEGF), epidermal growth factor and certain enzymes secreted by tumor cells, including MMPs, 
promote migration and metastasis (13). Substantial evidence has demonstrated that the overexpression of VEGF, MMP-2 and MMP-9 is associated with infiltration and metastasis of TSCC (14,15); therefore, it is conceivable that their downregulation may inhibit invasion and metastasis in TSCC.

The aim of the present study was to investigate the expression of VEGF, MMP-2 and MMP-9 in TSCC Tca8113 cells following exposure to high-LET carbon ions and low-LET $\mathrm{X}$-rays, and to provide some basic data for the efficacy of heavy ion radiation therapy against TSCC.

\section{Materials and methods}

Cell culture. The human TSCC cell line Tca8113 was obtained from the China Center for Type Culture Collection (Wuhan, China). Cells were cultured in RPMI-1640 medium (Thermo Fisher Scientific, Inc., Waltham, MA, USA) supplemented with $10 \%$ heat-inactivated fetal bovine serum (FBS; Minghai Biochem, Lanzhou, China), $100 \mathrm{U} / \mathrm{ml}$ penicillin and $100 \mu \mathrm{g} / \mathrm{ml}$ streptomycin, $1 \%$ sodium pyruvate and $2 \mathrm{mM}$ glutamine (all obtained from Thermo Fisher Scientific, Inc.) at $37^{\circ} \mathrm{C}$ with $5 \%$ $\mathrm{CO}_{2}$ and $95 \%$ humidity. Cells were seeded in $35 \mathrm{~mm}$ glass Petri dishes (Nunc GmbH, Wiesbaden, Germany), and cell density was adjusted to $5 \times 10^{5}$ cells $/ \mathrm{ml}$ at $24 \mathrm{~h}$ prior to irradiation. The cultured cells were divided into two groups; one group of cells were treated by X-ray, while the other were treated by heavy ion beam.

Irradiation procedure. The two groups of Tca8113 cells were irradiated at room temperature with carbon ions or $\mathrm{X}$-rays. The irradiation with carbon ions was conducted in the Heavy Ion Research Facility in Lanzhou (HIRFL) at the Institute of Modern Physics, Chinese Academy of Sciences (Lanzhou, China). Tca8113 cells were exposed to a carbon ion beam with energy of $250 \mathrm{MeV} / \mathrm{u}$ supplied by HIRFL. The LET value of the beam was adjusted to $75 \mathrm{keV} / \mu \mathrm{m}$ and the dose rate was $\sim 1 \mathrm{~Gy} / \mathrm{min}$. For X-ray irradiation, cell samples were treated at room temperature with an X-ray irradiation system (Faxitron RX-650; Faxitron Bioptics LLC, Tuscon, AZ, USA) at $50 \mathrm{kVp}$ with a dose rate of $0.5 \mathrm{~Gy} / \mathrm{min}$. The doses applied in this experiment were $0,1,2$ and 4 Gy for both irradiations. Following irradiation, the cells were incubated under normal culture conditions for 12, 24 and $48 \mathrm{~h}$. The control cells were sham-irradiated.

Cell invasion assay. Cell invasion assay was performed using Transwell inserts with $8-\mu \mathrm{m}$ pores and coated with Matrigel (BD Biosciences, Franklin Lakes, NJ, USA), which was used as a basement membrane equivalent, and is composed of extracellular matrix designed to mimic the typical matrices that tumor cells encounter during the invasion process in vivo. Cells irradiated with carbon ions or X-rays at doses of 0, 1 and 4 Gy were treated with trypsinase and resuspended in serum-free RPMI-1640, after which $200 \mu \mathrm{l}\left(2 \times 10^{5}\right.$ cells $\left./ \mathrm{ml}\right)$ cell suspension was added to the upper chambers. The lower chambers were filled with $600 \mu$ 1 RPMI-1640 supplemented with $10 \% \mathrm{FBS}$ as a chemo-attractant. Following incubation under normal culture conditions for $24 \mathrm{~h}$, the non-invading cells on the upper surface of the filters were scraped away using a cotton swab. The cells that had invaded to the lower surface of the filters were fixed in ethanol and stained with Giemsa at room temperature for $20 \mathrm{~min}$. Subsequently, the cells were counted in five random fields under a light microscope (Olympus, Tokyo, Japan) at x100 magnification.

Western blotting. Cells irradiated with carbon ions or X-rays at doses of 0,1 and 4 Gy were collected at 12, 24 and $48 \mathrm{~h}$ post-irradiation. The cells were rinsed twice with ice-cold PBS prior to being lysed in lysis buffer (Wuhan Boster Biological Technology, Ltd., Wuhan, China). Subsequently, the cell lysates were centrifuged at $16,100 \mathrm{x}$ g for $10 \mathrm{~min}$ at $4^{\circ} \mathrm{C}$. The supernatant was collected, and the amount of protein was estimated using a bicinchoninic acid protein assay kit (Bioworld Technology, Inc., St. Louis Park, MN, USA). Equal quantities of protein $(30 \mu \mathrm{g})$ were loaded onto an $8 \%$ SDS-PAGE gel and the separated proteins were transferred onto polyvinylidene difluoride membranes (Roche Diagnostics, Basel, Switzerland) for $1 \mathrm{~h}$ at $100 \mathrm{~V}$. After transfer, the membranes were blocked in $5 \%$ bovine serum albumin (BSA; Lanzhou Minhai Bioengineering Co., Ltd.) at room temperature for $2 \mathrm{~h}$ and subsequently incubated overnight at $4^{\circ} \mathrm{C}$ with anti-MMP-2 (cat. no. 4022), anti-MMP-9 (cat. no. 3852; Cell Signaling Technology, Inc., Danvers, MA, USA) or anti- $\beta$-actin (cat. no. TA-09; all used at 1:1,000; Beijing Zhongshan Golden Bridge Biotech Co., Ltd., Beijing, China). Blots were rinsed with TBS ( $\mathrm{pH} 7.4$ ) and $0.05 \%$ Tween-20, and incubated with horseradish peroxidase-conjugated anti-mouse monoclonal antibody (cat. no. ZB-2305) or anti-rabbit polyclonal antibody (cat. no. ZB-2301; both 1:2,000; Beijing Zhongshan Golden Bridge Biotech Co., Ltd.) for $2 \mathrm{~h}$ at $37^{\circ} \mathrm{C}$. Immunoreactive proteins were detected using the ECL western blotting kit (Bioworld Technology, Inc.). Bands were scanned and detected using a chemiluminescent imaging system (Tanon 4200 SF; Tanon Science and Technology Co., Ltd., Shanghai, China) and the density of bands were quantified using the Quantity One software (v4.4, Bio-Rad Laboratories, Inc., Hercules, CA, USA).

Indirect immunofluorescence assay. For indirect immunofluorescence, Tca8113 cells $\left(1 \times 10^{5}\right.$ cells $\left./ \mathrm{ml}\right)$ were grown on glass coverslips and cultured at $37^{\circ} \mathrm{C}$ at $5 \% \mathrm{CO}_{2}$ for $24 \mathrm{~h}$ until the cells were fully attached to the glass coverslips prior to irradiation. In order to confirm whether the effect of irradiation was dose-dependent, cells were irradiated with carbon ions or X-rays at doses of $0,1,2$ and $4 \mathrm{~Gy}$ and collected at 12, 24 and $48 \mathrm{~h}$ post-irradiation. Cells were fixed in $4 \%$ paraformaldehyde for $15 \mathrm{~min}$ at room temperature, then permeabilized with $0.1 \%$ Triton $\mathrm{X}-100$ for $2 \mathrm{~min}$, washed in PBS, and blocked in 5\% BSA (Lanzhou Minhai Bioengineering Co., Ltd.) at room temperature for $30 \mathrm{~min}$. Subsequently, the coverslips were washed and incubated with mouse anti-human monoclonal antibody VEGF (cat. no. ab1316; 1:200; Abcam, Cambridge, MA, USA) at $37^{\circ} \mathrm{C}$ for $2 \mathrm{~h}$, washed three times in PBS, and incubated with fluorescein-isothiocyanate-labeled donkey anti-mouse antibody IgG (cat. no. ab7057; 1:800; Abcam, Cambridge, MA, USA), at $37^{\circ} \mathrm{C}$ for $1 \mathrm{~h}$. Nuclear DNA was stained with DAPI (Sangon Biotech Co., Ltd., Shanghai, China) at room temperature for $10 \mathrm{~min}$. The coverslips were evaluated and images were captured using a fluorescence microscope (Olympus) at x1,000 magnification. 

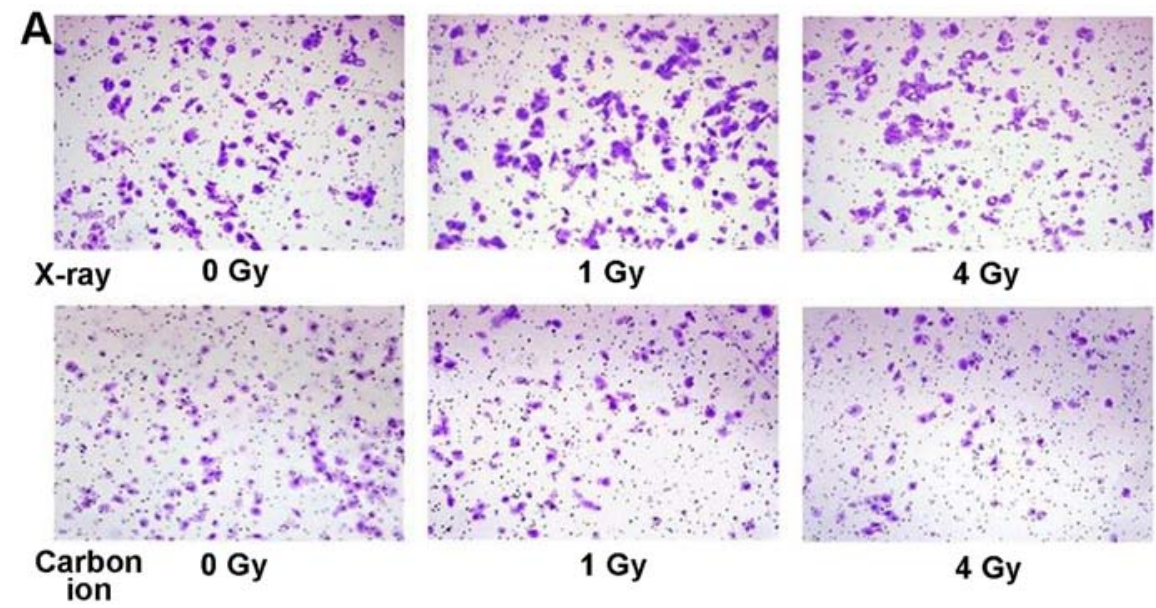

$1 \mathrm{~Gy}$

$4 \mathrm{~Gy}$

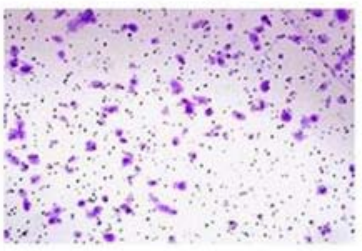

$1 \mathrm{~Gy}$

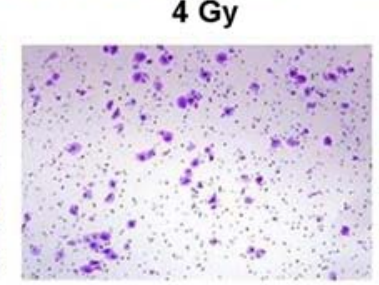

4 Gy

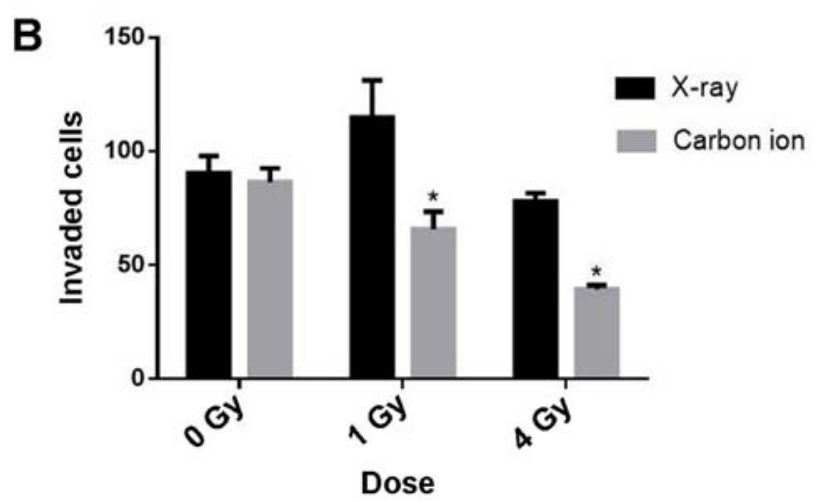

Figure 1. Cell invasion assay. (A) Invasive potential of Tca8113 cells treated with X-rays or carbon ions at different doses. x100 magnification was used. (B) Quantification of invasion assay results $(\mathrm{n}=3)$. ${ }^{*} \mathrm{P}<0.05$ vs. X-ray.

Statistical analysis. All experiments were repeated at least three times. Data are presented as the mean \pm standard deviation and analyzed using SPSS version 13.0 (SPSS, Inc., Chicago, IL, USA). Groups were compared using ANOVA with Bonferroni's post-hoc test. $\mathrm{P}<0.05$ was considered to indicate a statistically significant difference.

\section{Results}

Effects of irradiation on cell invasion. The cell invasion assay was used to investigate the effects of irradiation with carbon ions and X-rays on the invasion of Tca8113 cells. The rate of invasion in cells irradiated with carbon ions was decreased with increasing doses of radiation, and was significantly decreased compared with cells exposed to X-ray irradiation at the same dose $(\mathrm{P}<0.05$; Fig. 1).

Effects of irradiation on VEGF expression. The expression of VEGF in Tca8113 cells irradiated with carbon ions and $\mathrm{X}$-rays was evaluated by immunofluorescence (Figs. 2 and 3). Compared with the control cells (sham-irradiated), there was no significant change in VEGF expression at 12, 24 or $48 \mathrm{~h}$ after X-ray irradiation with different doses. However, VEGF was significantly downregulated at $24 \mathrm{~h}$ after carbon ion irradiation at a dose of $2 \mathrm{~Gy}$, and significantly decreased in a dose-dependent manner at $48 \mathrm{~h}$, as indicated in Fig. $4(\mathrm{P}<0.05)$.

Effects of irradiation on MMP-2 and MMP-9 protein expression. MMP-2 and MMP-9 expression were detected by western blot. Compared with the control cells (sham-irradiated), there was a significant increase in MMP-2 expression in Tca8113 cells treated with $\mathrm{X}$-rays at a low dose $(1 \mathrm{~Gy} ; \mathrm{P}<0.05$; Fig. 5A and B). However, there was no significant difference in MMP-9 expression among cells irradiated with the same dose of X-ray irradiation. In Tca8113 cells irradiated with carbon ions, MMP-2 expression was downregulated at the low dose (1 Gy) except $12 \mathrm{~h}$ post-irradiation and also decreased at the high dose (4 Gy) over time post-irradiation. Similar to MMP-2 expression, the level of MMP-9 expression also decreased in Tca8113 cells irradiated at the high dose (4 Gy), although no significant change was observed at the low dose $(1 \mathrm{~Gy} ; \mathrm{P}>0.05$; Fig. 6A and B).

\section{Discussion}

Successful treatment of TSCC is frequently complicated by invasion and metastasis, which may severely impact survival and quality of life in patients $(1,16-18)$. Radiotherapy provides an auxiliary treatment strategy for this disease. Although it is an effective strategy for local control of the primary tumor, recurrence and metastasis are frequently observed in patients with TSCC (19). Therefore, the suppression of invasion and metastasis are considered to be critical therapeutic targets for TSCC (20-22). Previous studies have demonstrated that high-LET particles, including carbon ions, are more effective compared with low-LET radiation, including X-rays, in suppressing tumor cell invasion $(12,23)$. However, the responses of tumor cells to radiation are different and complex $(24,25)$. 

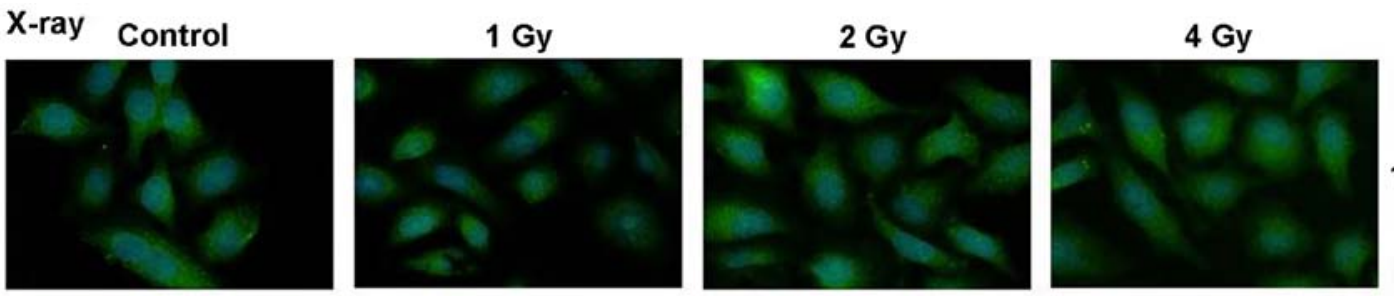

$12 \mathrm{~h}$
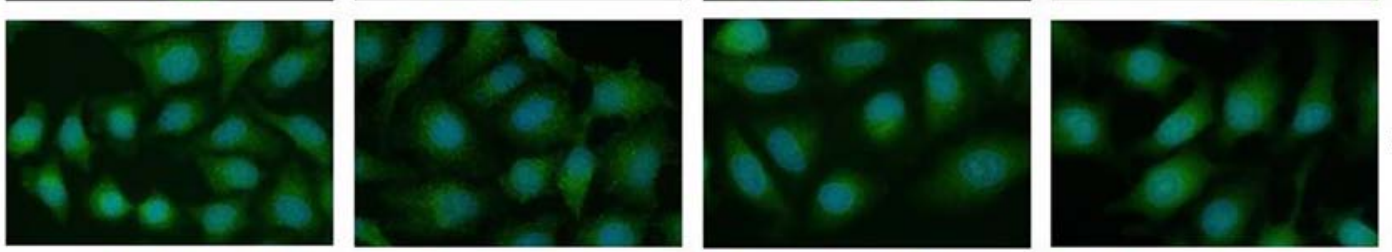

$24 \mathrm{~h}$
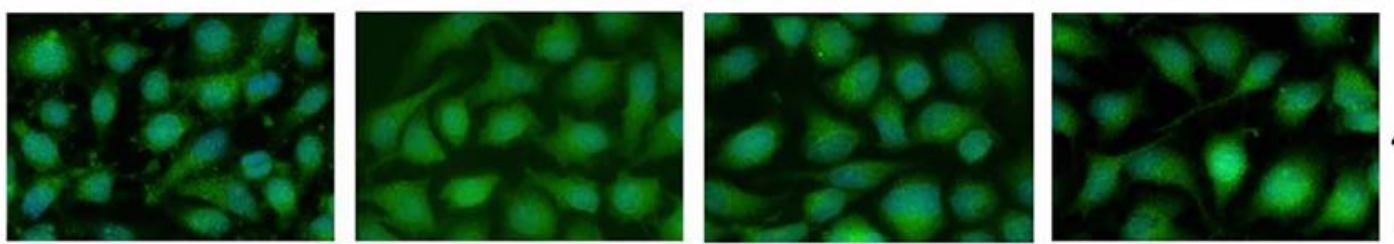

$48 \mathrm{~h}$

Figure 2. Expression of vascular endothelial growth factor (green) in Tca8113 cells irradiated with X-rays at different doses. An indirect immunofluorescence assay was performed at 12,24 or $48 \mathrm{~h}$ post-irradiation. x1000 magnification was used.

\section{Carbon ion}

Control
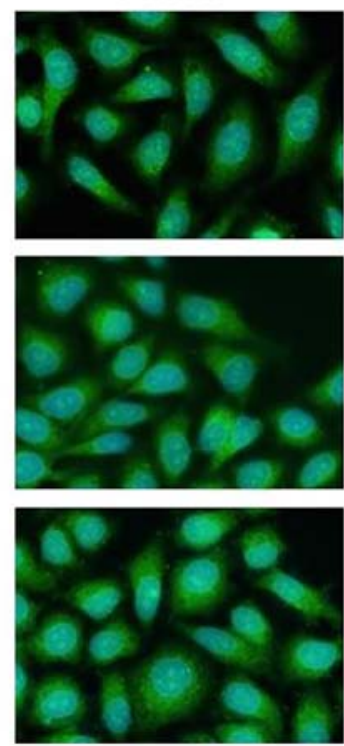

$1 \mathrm{~Gy}$
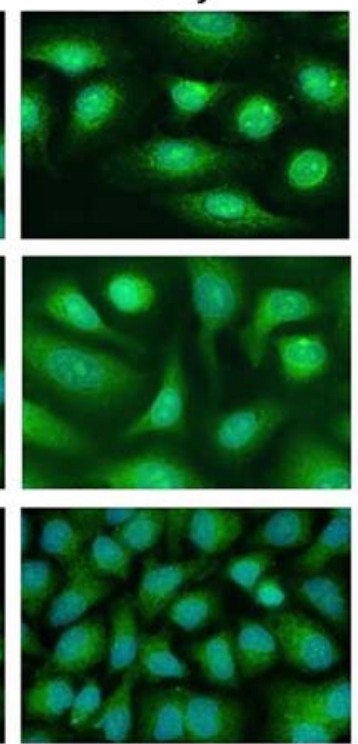

2 Gy
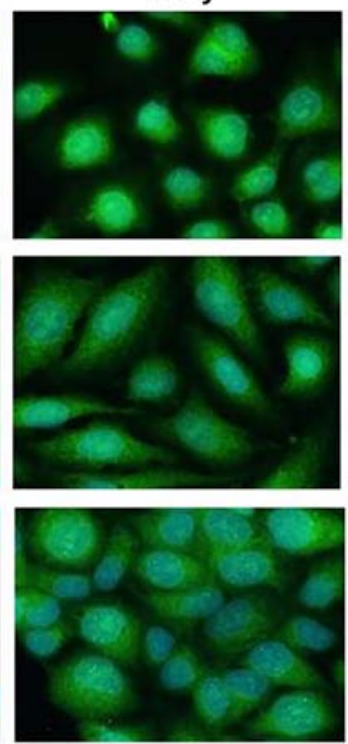

4 Gy

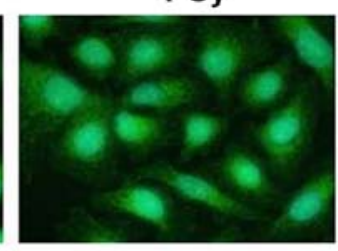

$12 \mathrm{~h}$

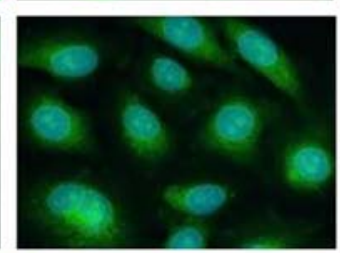

$24 \mathrm{~h}$

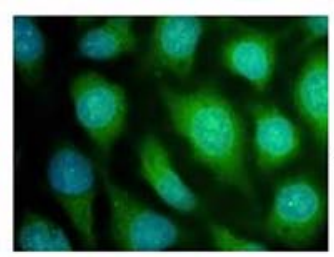

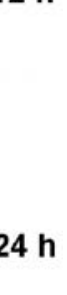

$48 \mathrm{~h}$

Figure 3. Expression of vascular endothelial growth factor in Tca8113 cells (green) irradiated with carbon ions at different doses. An indirect immunofluorescence assay was performed at 12,24 or $48 \mathrm{~h}$ post-irradiation. x1000 magnification was used.

The invasion of a malignant tumor is a complicated phenomenon involving angiogenesis, adhesion of the cell to the ECM, degradation of the ECM and invasion of the cell into the surrounding tissues $(26,27)$. The metastatic potential of the non-small cell lung cancer A549 cell line and the lung squamous cell carcinoma EBC-1 cell line has been reported to be inhibited by heavy ions (12), therefore we hypothesized that high-LET heavy ions may inhibit the metastatic potential of Tca8113 cells. Therefore, in the present study, the biological effects of heavy ion irradiation on cells were investigated, including invasion and the expression levels of molecules associated with metastasis, including MMP-2, MMP-9 and VEGF.
There are numerous factors associated with metastatic potential. During the process of tumor invasion and metastasis, the basement membrane, which mainly consists of type IV collagen, is degraded by numerous types of enzyme, including serine proteinases, cysteine proteinases and MMPs (13). Among the secreted MMPs, MMP-2 and MMP-9 serve important roles in tumor invasion and metastasis $(28,29)$. Therefore, the aim of the present study was to determine whether MMP-2 or MMP-9 expression was altered in response to irradiation in malignant tumor cells. Wild-Bode et al (30) demonstrated that irradiating glioma cells with sub-lethal X-ray doses resulted in an increase in MMP-2 activity and promoted invasiveness of the cells. Similar findings 

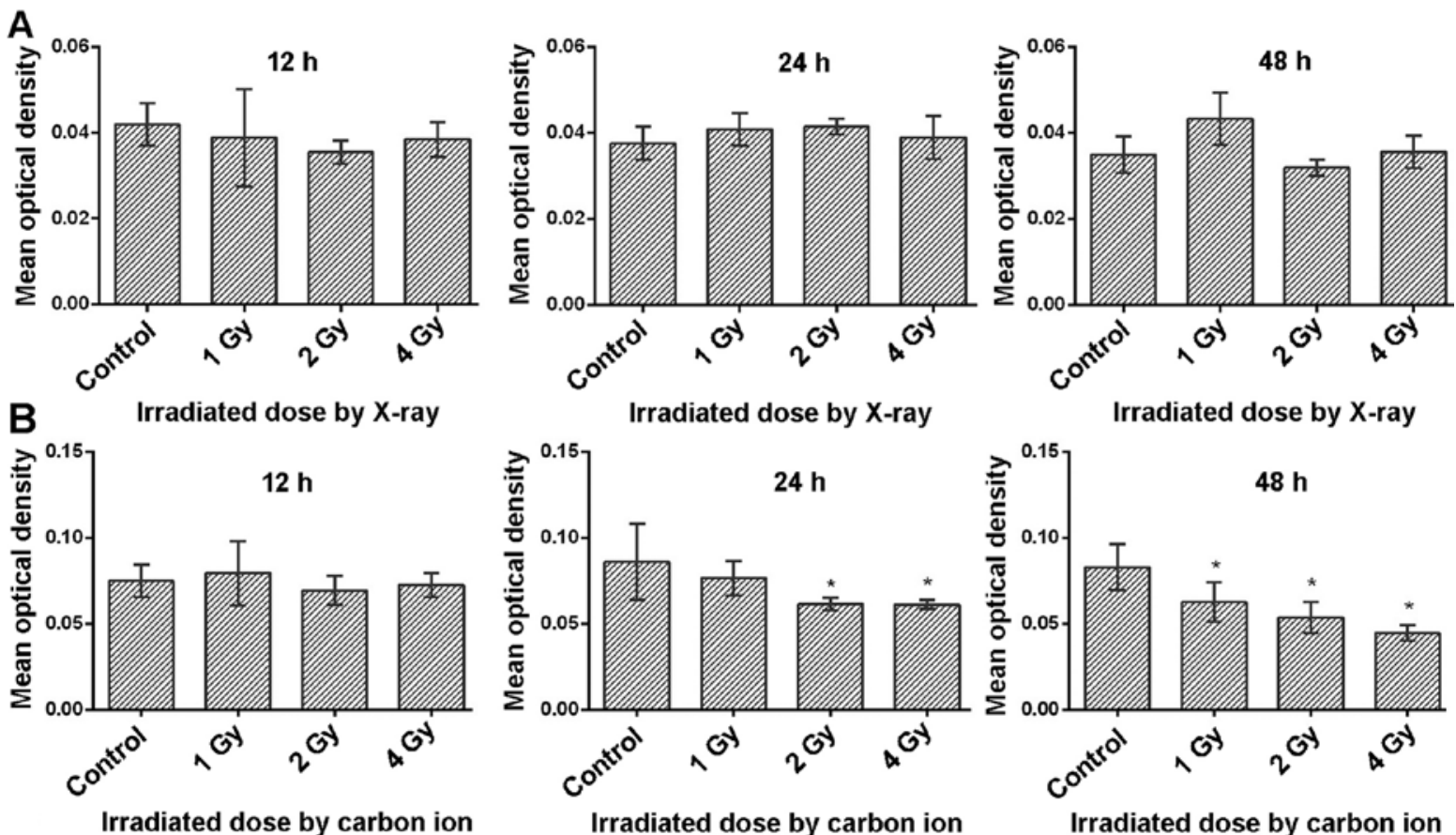

Irradiated dose by X-ray

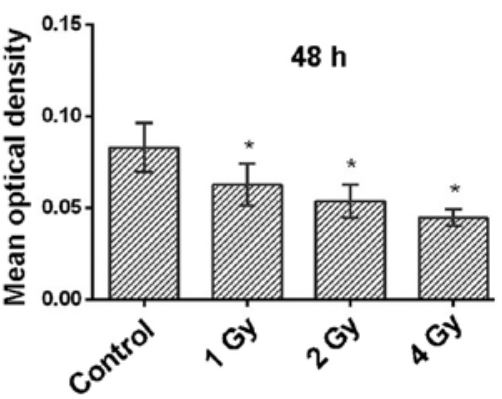

Irradiated dose by carbon ion

Figure 4. Quantification of vascular endothelial growth factor in Tca8113 cells irradiated with (A) X-rays and (B) carbon ions. "P<0.05 vs. control group.

A

1 Gy

4 Gy
C $\quad 12 \mathrm{~h} \quad 24 \mathrm{~h} \quad 48 \mathrm{~h}$
C $\quad 12 \mathrm{~h} \quad 24 \mathrm{~h} \quad 48 \mathrm{~h}$

MMP-2

MMP-9

$\beta$-actin
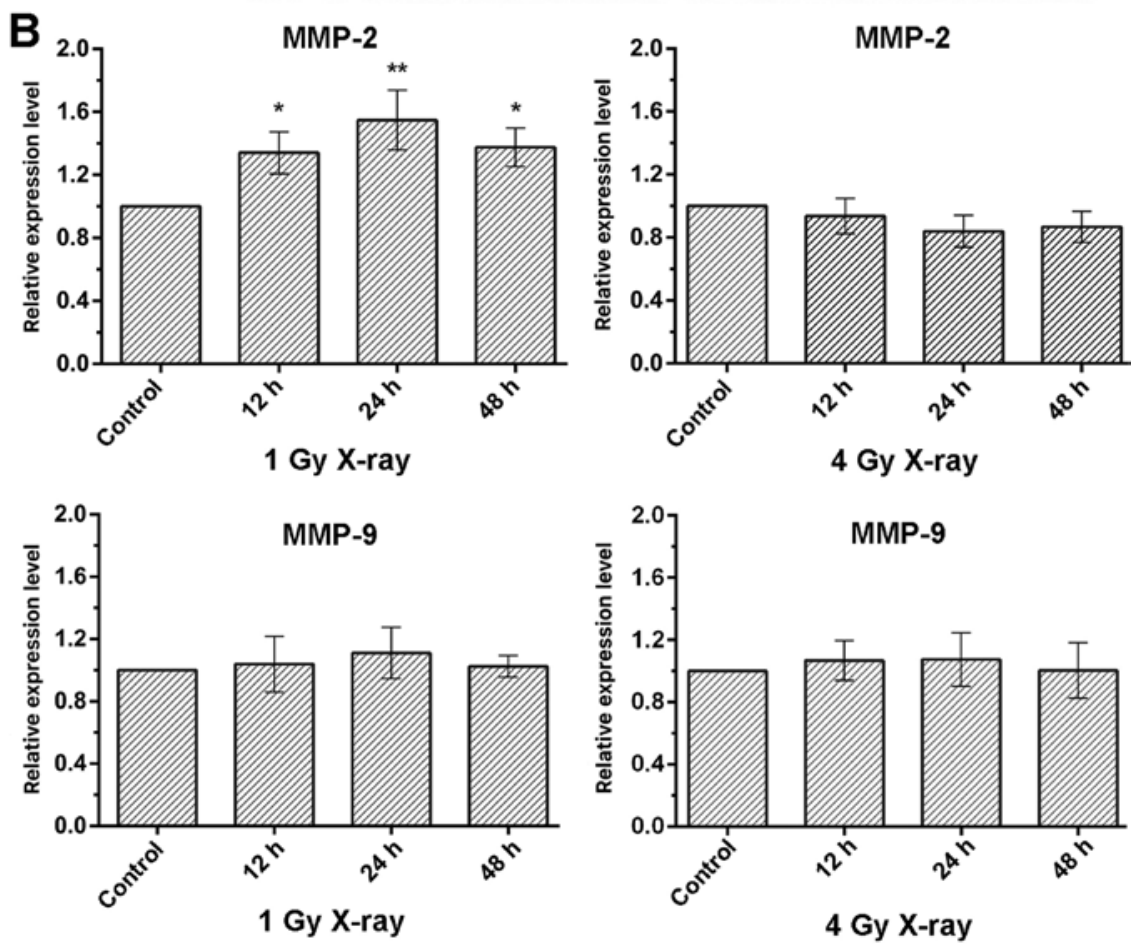

Figure 5. Effects of X-ray irradiation on MMP-2 and MMP-9 expression. (A) Western blot analysis. (B) Quantification of MMP-2 and MMP-9 expression. ${ }^{*} \mathrm{P}<0.05,{ }^{* *} \mathrm{P}<0.01$ vs. control group. MMP, matrix metalloproteinase. 

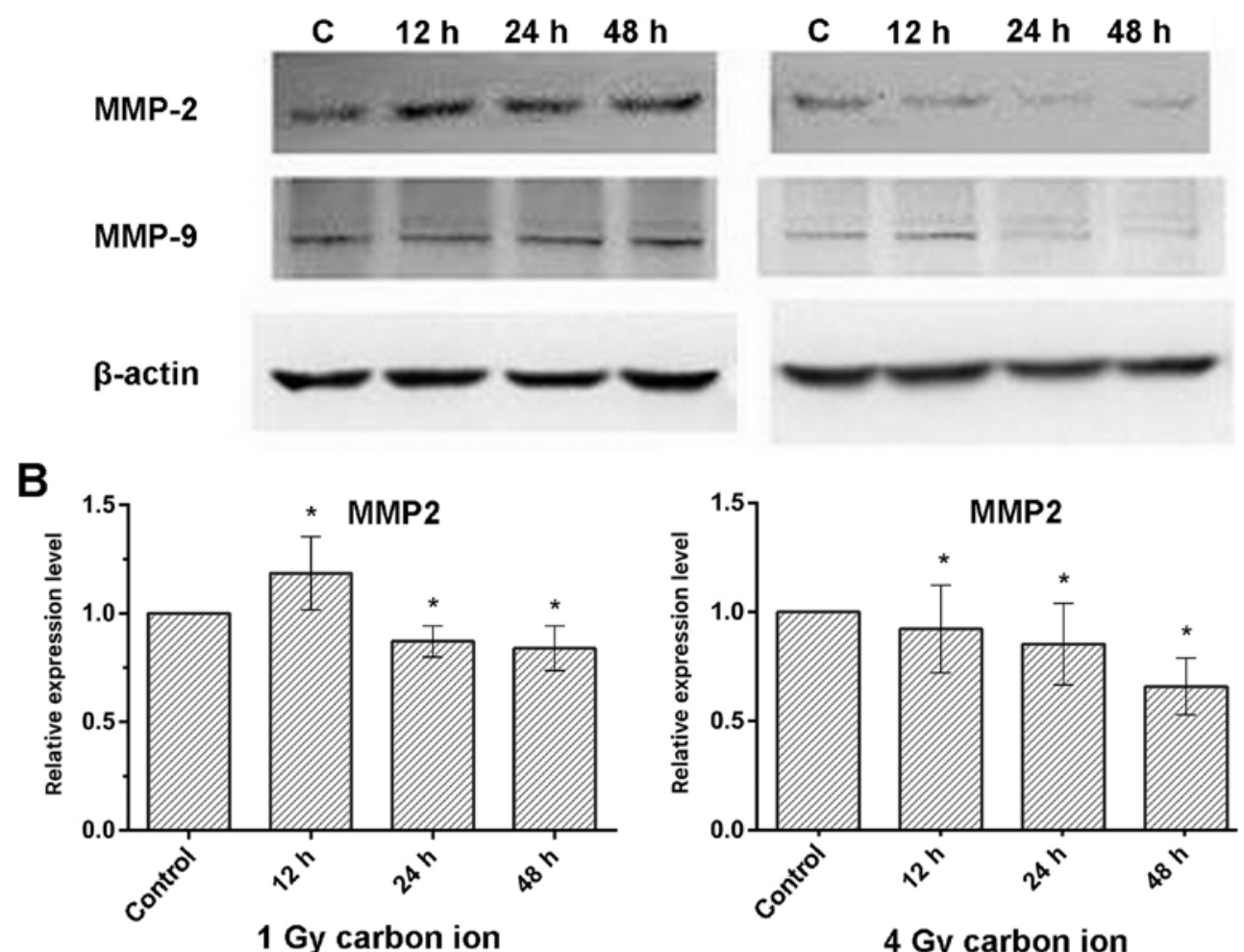

4 Gy carbon ion
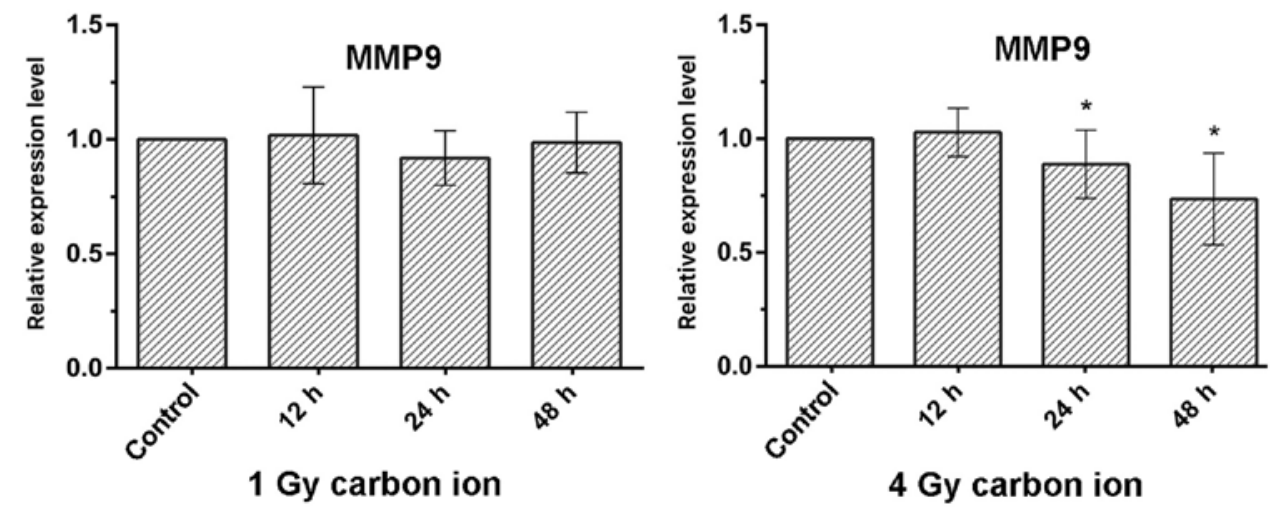

4 Gy carbon ion

Figure 6. Effects of carbon ion irradiation on MMP-2 and MMP-9 expression. (A) Western blot analysis. (B) Quantification of MMP-2 and MMP-9 expression. ${ }^{*} \mathrm{P}<0.05$ vs. control group. MMP, matrix metalloproteinase.

have been reported for other cancer cell types, including those of the liver, lung and pancreas (31-33). The results of the present study additionally demonstrated that the expression level of MMP-2 increased following X-ray irradiation of $1 \mathrm{~Gy}$ in Tca8113 cells. Notably, for Tca8113 cells irradiated with heavy ions, the invasive ability significantly decreased in a dose-dependent manner, and the expression of MMP-2 protein was downregulated at both low dose (1 Gy) and a high doses (4 Gy) over time, in accordance with the findings by Ogata et al (23). There was no significant difference in MMP-9 expression in Tca8113 cells irradiated with different doses of X-rays (1,2 and 4 Gy) and a low dose of carbon ions (1 Gy) at the same time points, but the expression of MMP-9 was decreased in Tca8113 cells exposed to a high dose of carbon ions (4 Gy). These results are consistent with a previous study (11), suggesting that high-LET heavy ions may suppress the invasiveness of Tca8113 cells via downregulating MMP-2 and MMP-9 expression.
VEGF, a heparin-binding glycoprotein, has five known isoforms, and is an important growth factor in the progression and angiogenesis of malignant tumors (34). It was demonstrated that radiation induces VEGF expression in a range of tumor cell lines (35), and that certain tumor cells protect themselves against radiotherapy via the release of VEGF (36). In the present study, there was no notable difference in the expression of VEGF in Tca8113 cells irradiated with X-rays compared with non-irradiated cells. By contrast, VEGF levels significantly decreased in cells irradiated with carbon ions compared with non-irradiated cells supporting the results of a previous study by Liu et al (37), who reported that carbon ion radiation decreased VEGF secretion in lung adenocarcinoma A549 cells. As the immunofluorescence assay can only show the location of the target protein and cannot detect the molecular weight of the protein, the effect of irradiation on VEGF expression needs to be confirmed using western blot analysis in future experiments. One possible explanation for 
the carbon ion radiation mediated decrease may be that radiation with carbon ions may cause more complex and irreparable clustered DNA damage compared with X-rays. DNA repair is inefficient following high-LET particle irradiation, which may lead to chromosomal damage and eventually, cell death $(38,39)$. Further studies are required in order to improve understanding of the mechanism of action of carbon ions on organisms.

In summary, the present study indicated that high-LET carbon ion radiation has the potential to decrease Tca8113 cell invasion in a dose-dependent manner and this effect may be via the inhibition of MMP-2, MMP-9 and VEGF. These findings provide evidence that heavy-ion radiation therapy may be superior to radiotherapy with conventional X-rays for the clinical management of TSCC.

\section{Acknowledgements}

The authors would like to thank Dr Xiaodong Jin (Institute of Modern Physics, Chinese Academy of Sciences) for his advice with regards to conducting this experiment.

\section{Funding}

This study was supported by the National Natural Science Foundation of China (grant no. 81260403) and the Gansu Provincial Youth Science and Technology Fund Project (grant no. 17JR5RA275).

\section{Availability of data and materials}

The datasets used and/or analyzed during the present study are available from the corresponding author on reasonable request.

\section{Authors' contributions}

ZF and CL designed the experiments and wrote the draft manuscript. QZ, WM, TL and LX participated in the experiments and analysis, and prepared the background research. QL designed the experiments and revised the final manuscript. All authors read and approved the final manuscript.

\section{Ethics approval and consent to participate}

Not applicable.

\section{Patient consent for publication}

Not applicable.

\section{Competing interests}

The authors declare that that they have no competing interests.

\section{References}

1. Jemal A, Bray F, Center MM, Ferlay J, Ward E and Forman D Global cancer statistics. CA Cancer J Clin 61: 69-90, 2011.

2. Chandler K, Vance C, Budnick S and Muller S: Muscle invasion in oral tongue squamous cell carcinoma as a predictor of noda status and local recurrence: Just as effective as depth of invasion? Head Neck Pathol 5: 359-363, 2011.
3. Mücke T, Mitchell DA, Wagenpfeil S, Ritschl LM, Wolff KD and Kanatas A: Incidence and outcome for patients with occult lymph node involvement in T1 and T2 oral squamous cell carcinoma: A prospective study. BMC Cancer 14: 346, 2014.

4. Ganly I, Patel S and Shah J: Early stage squamous cell cancer of the oral tongue-clinicopathologic features affecting outcome. Cancer 118: 101-111, 2012.

5. Vissink A, Jansma J, Spijkervet FK, Burlage FR and Coppes RP Oral sequelae of head and neck radiotherapy. Crit Rev Oral Biol Med 14: 199-212, 2003.

6. Wong HM: Oral complications and management strategies for patients undergoing cancer therapy. ScientificWorldJournal 2014: 581795, 2014.

7. Silveira MH, Dedivitis RA, Queija DS and Nascimento PC Quality of life in swallowing disorders after nonsurgical treatment for head and neck cancer. Int Arch Otorhinolaryngol 19: 46-54, 2015.

8. Kraft G: The radiobiological and physical basis for radiotherapy with protons and heavier ions. Strahlenther Onkol 166: 10-13, 1990.

9. Halperin EC: Particle therapy and treatment of cancer. Lancet Oncol 7: 676-685, 2006

10. Kamada T, Tsujii H, Blakely EA, Debus J, De Neve W, Durante M, Jäkel O, Mayer R, Orecchia R, Pötter R, et al: Carbon ion radiotherapy in Japan: An assessment of 20 years of clinical experience. Lancet Oncol 16: e93-e100, 2015.

11. Takahashi Y, Teshima T, Kawaguchi N, Hamada Y, Mori S, Madachi A, Ikeda S, Mizuno H, Ogata T, Nojima K, et al: Heavy ion irradiation inhibits in vitro angiogenesis even at sublethal dose. Cancer Res 63: 4253-4257, 2003.

12. Akino $\mathrm{Y}$, Teshima T, Kihara A, Kodera-Suzumoto $\mathrm{Y}$, Inaoka M, Higashiyama S, Furusawa Y and Matsuura N: Carbon-ion beam irradiation effectively suppresses migration and invasion of human non-small-cell lung cancer cells. Int J Radiat Oncol Biol Phys 75: 475-481, 2009.

13. Koontongkaew S: The tumor microenvironment contribution to development, growth, invasion and metastasis of head and neck squamous cell carcinomas. J Cancer 4: 66-83, 2013.

14. Kim SH, Cho NH, Kim K, Lee JS, Koo BS, Kim JH, Chang JH and Choi EC: Correlations of oral tongue cancer invasion with matrix metalloproteinases (MMPs) and vascular endothelial growth factor (VEGF) expression. J Surg Oncol 93: 330-337, 2006.

15. Matsui T, Shigeta T, Umeda M and Komori T: Vascular endothelial growth factor C (VEGF-C) expression predicts metastasis in tongue cancer. Oral Surg Oral Med Oral Pathol Oral Radiol 120: 436-442, 2015.

16. Liu WH, Li X, Zhu XL, Hou ML and Zhao W: CD63 inhibits the cell migration and invasion ability of tongue squamous cell carcinoma. Oncol Lett 15: 9033-9042, 2018.

17. Sano D and Myers JN: Metastasis of squamous cell carcinoma of the oral tongue. Cancer Metastasis Rev 26: 645-662, 2007.

18. Olaleye O, Ekrikpo U, Lyne O and Wiseberg J: Incidence and survival trends of lip, intra-oral cavity and tongue base cancers in south-east England. Ann R Coll Surg Engl 97: 229-234, 2015.

19. Sun C, Wang X, Zhong Z, Wang W, Luo J, Chen X, Chu H, Tao X and Yang A: Differences in clinicopathological characteristics and prognosis between primary and postirradiation tongue squamous cell carcinoma. J Oral Maxillofac Surg 75: 2235-2241, 2017.

20. Roy R, Yang J and Moses MA: Matrix metalloproteinases as novel biomarkers and potential therapeutic targets in human cancer. J Clin Oncol 27: 5287-5297, 2009.

21. Jiang L, Liu X, Kolokythas A, Yu J, Wang A, Heidbreder CE, Shi F and Zhou X: Downregulation of the Rho GTPase signaling pathway is involved in the microRNA-138-mediated inhibition of cell migration and invasion in tongue squamous cell carcinoma. Int J Cancer 127: 505-512, 2010.

22. Shang B, Cao Z and Zhou Q: Progress in tumor vascular normalization for anticancer therapy: Challenges and perspectives. Front Med 6: 67-78, 2012.

23. Ogata T, Teshima T, Kagawa K, Hishikawa Y, Takahashi Y, Kawaguchi A, Suzumoto Y, Nojima K, Furusawa Y and Matsuura N: Particle irradiation suppresses metastatic potential of cancer cells. Cancer Res 65: 113-120, 2005.

24. Hill RP: The changing paradigm of tumour response to irradiation. Br J Radiol 90: 20160474, 2017.

25. Matsuda S, Furuya K, Ikura M, Matsuda T and Ikura T: Absolute quantification of acetylation and phosphorylation of the histone variant $\mathrm{H} 2 \mathrm{AX}$ upon ionizing radiation reveals distint cellular responses in two cancer cell lines. Radiat Environ Biophys 54: $403-411,2015$ 
26. Chambers AF, Groom AC and MacDonald IC: Dissemination and growth of cancer cells in metastatic sites. Nat Rev Cancer 2: 563-572, 2002.

27. Joyce JA and Pollard JW: Microenvironmental regulation of metastasis. Nat Rev Cancer 9: 239-252, 2009.

28. Xue Q, Cao L, Chen XY, Zhao J, Gao L, Li SZ and Fei Z: High expression of MMP9 in glioma affects cell proliferation and is associated with patient survival rates. Oncol Lett 13: 1325-1330, 2017.

29. Fan HX, Li HX, Chen D, Gao ZX and Zheng JH: Changes in the expression of MMP2, MMP9, and ColIV in stromal cells in oral squamous tongue cell carcinoma: Relationships and prognostic implications. J Exp Clin Cancer Res 31: 90, 2012.

30. Wild-Bode C, Weller M, Rimner A, Dichgans J and Wick W: Sublethal irradiation promotes migration and invasiveness of glioma cells: Implications for radiotherapy of human glioblastoma. Cancer Res 61: 2744-2750, 2001.

31. Araya J, Maruyama M, Sassa K, Fujita T, Hayashi R, Matsui S, Kashii T, Yamashita N, Sugiyama E and Kobayashi M: Ionizing radiation enhances matrix metalloproteinase- 2 production in human lung epithelial cells. Am J Physiol Lung Cell Mol Physiol 280: L30-L38, 2001.

32. Qian LW, Mizumoto K, Urashima T, Nagai E, Maehara N, Sato N, Nakajima M and Tanaka M: Radiation-induced increase in invasive potential of human pancreatic cancer cells and its blockade by a matrix metalloproteinase inhibitor, CGS27023. Clin Cancer Res 8: 1223-1227, 2002.

33. Cheng JC, Chou CH, Kuo ML and Hsieh CY: Radiation-enhanced hepatocellular carcinoma cell invasion with MMP-9 expression through PI3K/Akt/NF-kappaB signal transduction pathway. Oncogene 25: 7009-7018, 2006.

34. Flickinger I, Rütgen BC, Gerner W, Calice I, Tichy A, Saalmüller A and Kleiter M: Radiation up-regulates the expression of VEGF in a canine oral melanoma cell line. J Vet Sci 14: 207-214, 2013.
35. Gorski DH, Beckett MA, Jaskowiak NT, Calvin DP, Mauceri HJ, Salloum RM, Seetharam S, Koons A, Hari DM, Kufe DW and Weichselbaum RR: Blockage of the vascular endothelial growth factor stress response increases the antitumor effects of ionizing radiation. Cancer Res 59: 3374-3378, 1999.

36. Park JS, Qiao L, Su ZZ, Hinman D, Willoughby K, McKinstry R, Yacoub A, Duigou GJ, Young CS, Grant S, et al: Ionizing radiation modulates vascular endothelial growth factor (VEGF) expression through multiple mitogen activated protein kinase dependent pathways. Oncogene 20: 3266-3280, 2001.

37. Liu Y, Liu Y, Zhang H, Sun C, Zhao Q, Di C, Li H, Gan L and Wang Y: Effects of carbon-ion beam irradiation on the angiogenic response in lung adenocarcinoma A549 cells. Cell Biol Int 38: 1304-1310, 2014

38. Mohamad O, Sishc BJ, Saha J, Pompos A, Rahimi A, Story MD, Davis AJ and Kim DWN: Carbon ion radiotherapy: A review of clinical experiences and preclinical research, with an emphasis on DNA damage/repair. Cancers (Basel) 9: pii: E66, 2017.

39. Hagiwara $Y$, Niimi A, Isono $M$, Yamauchi $M$, Yasuhara $T$, Limsirichaikul S, Oike T, Sato H, Held KD, Nakano T and Shibata A: 3D-structured illumination microscopy reveals clustered DNA double-strand break formation in widespread $\gamma \mathrm{H} 2 \mathrm{AX}$ foci after high LET heavy-ion particle radiation. Oncotarget 8: 109370-109381, 2017.

\footnotetext{
This work is licensed under a Creative Commons Attribution-NonCommercial-NoDerivatives 4.0 International (CC BY-NC-ND 4.0) License.
} 